\title{
The Anatomy of Persistence: Remediation and Science Identity Perceptions in Undergraduate Anatomy and Physiology
}

\author{
Emily A. Royse ${ }^{1}$, Elliot Sutton ${ }^{1}$, Melanie E. Peffer ${ }^{2} \&$ Emily A. Holt ${ }^{1}$ \\ ${ }^{1}$ School of Biological Sciences, University of Northern Colorado, Greeley, Colorado, United States of America \\ ${ }^{2}$ Institute of Cognitive Science, and Molecular, Cellular, and Developmental Biology, University of Colorado \\ Boulder, Boulder, Colorado, United States of America \\ Correspondence: Emily A. Royse, School of Biological Sciences, University of Northern Colorado, Greeley, \\ Colorado, 80639, United States of America.
}

Received: June 30, 2020

Accepted: August 4, 2020

Online Published: August 5, 2020

doi:10.5430/ijhe.v9n5p283

URL: https://doi.org/10.5430/ijhe.v9n5p283

\begin{abstract}
Undergraduate Anatomy and Physiology (A\&P) courses are gateway courses nursing and allied health students must pass before progressing through their academic programs. Many students need to retake the course to receive grades acceptable to progress in their programs, but identifying students at risk of failure may help instructors extend support. In this study, we examined self-efficacy and science identity as potential predictors of student success in these courses, and, by extension, a potential way to identify students at risk of failing. We found that science identity, and not self-efficacy nor completion of science prerequisite courses, explained the most variance when predicting A\&P final grade in hierarchical regression. Additionally, we interviewed a purposive sample of students retaking the course to explore their experiences and perceptions of these constructs in A\&P over multiple enrollments. Students retaking the course described their experiences of being "biology people" in their interviews, further suggesting that having a science identity is relevant to A\&P students and may be leveraged to support students in A\&P contexts.
\end{abstract}

Keywords: science identity, self-efficacy, social cognitive theory, biology education, mixed methods

\section{Introduction}

Undergraduate Anatomy and Physiology (A\&P) courses are biology service courses that cover introductory biological topics related to human anatomy and homeostasis for students studying to enter nursing and allied health fields. Anecdotally, these courses are rife with student retention problems (Griff, 2016; Vitali, Blackmore, Mortazavi, \& Anderton, 2020). While high school under-preparation contributes to poor performance in these introductory classes (Anderton, Evans, \& Chivers, 2016), it does not account for much of the variance that explains the traditionally high Drop-Fail-Withdraw (DFW) rate in A\&P courses (Gultice, Witham, \& Kallmeyer, 2015). While nursing and allied health fields have a growing need for professionals to be trained and enter the workforce (Liu, Goryakin, Maeda, Bruckner, \& Scheffler, 2017), A\&P courses can become gateways that many students do not pass through. Some students may opt to attempt the course again, or remediate, after failing or receiving a passing grade that is unsatisfactory to make progress in their programs (Entezari \& Javdan, 2016; Wehrman, Ryan, \& Auerbach, 2020). While instructors may anecdotally postulate why their students retake their courses, scant research literature explains which students retake courses and why. Existing research in A\&P contexts suggests that gender, ethnicity, major of study, and SAT scores may predict student remediation, yet these factors do not account for all the variance (Schutte, 2016). A\&P courses cover disciplinary topics known to be academically challenging for undergraduate students (Slominski, Grindberg, \& Momsen, 2019; Sturges \& Maurer, 2013), but examining factors that contribute to student success in these courses, such as student affect and college course preparation (Harris, Hannum, \& Gupta, 2004), is one step in exploring how to tangibly support students so they can make progress toward their personal ambitions. Additionally, early identification of students who may be at risk for needing remediation (Vitali et al., 2020) and exploring both affective and academic at-risk factors may better support students' progress in their allied health programs (Goradia \& Bugarcic, 2019). Indeed, calls to investigate affect in biology education contexts suggest that affect could help inform or possibly predict how students succeed in biology courses like A\&P (Flowers \& Banda, 2016; Trujillo \& Tanner, 2014). 
Social Cognitive Theory is a historically fruitful lens through which to view student affect, and may be particularly relevant when examining affect relating to remediation, as persisting despite academic failure can be emotionally burdensome (Ajjawi, Dracup, Zacharias, Bennett, \& Boud, 2020). Bandura (1986) described how behavior, personal factors (i.e., affect or sense of self), and the environmental systems in which people are situated are all influencing factors to how people learn and achieve goals. Self-efficacy, defined as a person's self-assessment of their ability to complete a given task, is one such affective factor shown to be predictive of student academic achievement and persistence (Bandura, 1997; Zimmerman, 2000). For students entering nursing programs, low self-efficacy in science contexts is common (Caon \& Treagust, 1993), and in one study, low self-efficacy for science tasks predicted lower academic performance in nursing school courses (Andrew, 1998). The challenges of learning science that nursing students experience have been documented globally, but McVicar, Andrew, and Kemble (2015) suggest that this "bioscience problem" may be best remediated by both better prerequisite preparation and by supporting student self-efficacy.

While examining student self-efficacy provides insight into how confident students are in their ability to complete situated tasks, investigating students' sense of self is another perspective that could explain student outcomes in A\&P courses. Science identity, or how one feels that they relate to a science domain, is composed of self-assessment of competence, performance, interest, and recognition, and has been shown to be an important predictor of persistence in STEM fields, especially for minoritized groups (Carlone \& Johnson, 2007; Hazari, Sonnert, Sadler, \& Shanahan, 2010). Science identity is increasingly a construct of interest in research literature, as it has been implicated in persistence in physics (Hazari et al., 2010), engineering (Godwin, Potvin, Hazari, \& Lock, 2016), math (Cribbs, Hazari, Sonnert, \& Sadler, 2015), and graduate-level biology (Carlone \& Johnson, 2007). However, the persistence described in these studies is tied to long-term career pursuit and academic program completion, while student persistence through smaller goals, such as completing or remediating a single course, has not been examined through this lens. Additionally, nursing and allied health are not considered basic sciences or STEM fields, and so it is unknown whether students in A\&P courses relate to having a science identity and if that science identity relates to short-term or long-term persistence in this context.

\subsection{Study Purpose and Research Questions}

Our study investigated self-efficacy and science identity as it relates to course outcomes and remediation in A\&P contexts. Considering that the competence and performance subconstructs within science identity align closely with the definition of self-efficacy, examining both constructs in tandem explores self-assessment of both academic and long-term goals (Flowers \& Banda, 2016). We utilized a mixed methods approach to address the research questions:

(1) How do science identity, self-efficacy, and college course preparation predict academic outcomes for students enrolled in A\&P courses;

(2) what differences in student affect exist between re-takers (i.e., students retaking the course) and first-timers (i.e., students taking the course for the first time); and

(3) among re-takers, what experiences inform a student's decision to retake A\&P, illustrate how they define science identity, and contextualize their academic and professional goals?

\section{Methods}

\subsection{Participants}

Data collection for this study was conducted in accordance with the permission of the Institutional Review Board of the university where the study took place (Project \#1312887-3). The context for this study was a public, regional university in the western United States, which serves approximately 9,400 undergraduate students per year. Participants were recruited during the Fall 2018 semester from one section of an Introductory Anatomy and Physiology (A\&P) course and were compensated with a small amount of extra credit. This course is taught in the school's biology department by biology faculty and has no required prerequisite courses, though many students take introductory chemistry or biology classes before A\&P to fulfill other requirements for their majors. It is the first of a two-course sequence required before students may apply for the school's competitive nursing program. At this institution, A\&P also serves as a prerequisite for majors that feed into allied health careers, including nutrition, sports and exercise science, and audiology.

In the Fall 2018 semester cohort, 84 students consented to participate in this research and completed the first of two surveys. Of these students who participated in this first survey, 83 completed the course and were included in our pretest dataset. We had a low response rate $(\mathrm{n}=44)$ for the second survey, which included demographic information questions. Those who did respond identified primarily as female $(\mathrm{n}=36$; male $=5$; nonbinary $=1$; declined to report $=$ $2)$, and the majority were non-Hispanic white $(\mathrm{n}=33)$, followed by Latino/Hispanic American $(\mathrm{n}=3)$ or other 
racial/ethnic origins $(n=3)$. The participants represented many of the allied health majors for which A\&P is a prerequisite biology course, with the majority of students coming from nursing $(\mathrm{n}=11)$, sports and exercise science $(\mathrm{n}=11)$, audiology $(\mathrm{n}=11)$, and nutrition programs $(\mathrm{n}=7)$, though some students reported their major as psychology $(n=2)$, anthropology $(n=1)$, or biology $(n=1)$. As a 200-level course, the majority of students enrolled were underclassmen (freshman $=3$, sophomore $=21$, junior $=12$, senior $=8$ ).

Potential interview participants for the qualitative portion of our study were identified as students who reported they had previously taken an undergraduate A\&P course before enrolling in this course. For our research, A\&P courses taken at community colleges qualified as a previous attempt, but concurrent enrollment and high school A\&P courses were not considered a previous attempt (though nine students did report having taken an A\&P course in high school). Of the 83 participants in the pretest dataset, 28 reported that they were retaking the course after a previous attempt at the current institution or an analogous A\&P course at another institution. We decided in our analysis that students who withdrew from the previous course would not be considered re-takers, as they would not have been exposed to the entire curriculum, leaving a final pool of 27 re-takers. Chi-square analysis demonstrated no difference between the first-timers and re-takers by gender $(=1.07, \mathrm{df}=3, p=.785)$ or major $(=9.09, \mathrm{df}=6, p=.169)$. There was not a sufficient response rate to conduct a Chi-square analysis for re-taker status across ethnicities.

From this pool of re-takers, participants were randomly selected and invited to complete an interview with one of the members of the research team. Of the 27 students who reported they were retaking the course, $92.6 \%$ were invited to complete an interview, and we had a $25.6 \%$ response rate to the interview invitations. Of those respondents, $71.4 \%$ completed an interview, resulting in our sample size of five. Interviewees were compensated with a $\$ 10$ gift certificate. While a sample size of five participants is relatively small, it is acceptable for phenomenology, given that thematic saturation is reached (Creswell, 2013). After we had completed the five interviews, we noticed that interviewee responses were consistent with one another and no new ideas were emerging, and so we stopped recruiting interview participants at that time.

\subsection{Research Design}

We chose a sequential explanatory mixed methods approach, as our research questions necessitated primarily quantitative analyses, but these analyses were followed and enriched by qualitative interview interpretations (Creswell, 2014). We utilized a phenomenological approach to qualitative data collection and analysis to examine and richly describe the shared experiences of students retaking A\&P (Moustakas, 1994). Quantitative methods consisted of distributing pretest and posttest surveys to all participants with metrics to assess self-efficacy and science identity to address our first two research questions. The pretest was distributed via Qualtrics during the fifth week of a 16-week semester, qualitative interviews took place between weeks 8-14, and the posttest was distributed during weeks 13-15 of the semester to students who had completed the pretest. The interviews allowed us to address our third research question, as we probed their experiences of and perspectives on science identity and self-efficacy in the context of taking the course more than once. After the conclusion of the semester, the instructor for the course provided the researchers with the final course grades of all participants.

\subsection{Quantitative Data Collection and Analysis}

The pretest and posttest consisted of three previously published metrics to capture students' self-efficacy and science identity. One self-efficacy measure came from the Motivated Strategies for Learning Questionnaire (MSLQ; Pintrich, Smith, Garcia, \& McKeachie, 1993), which has several independent subscales meant to capture different components of students' motivations in academic settings and learning behaviors. We used only the self-efficacy subscale of the MSLQ, consisting of eight Likert-style items anchored on seven points (i.e., one = not at all true, seven = very true); student responses to the items are averaged to give a single numeric score for self-efficacy. Subscales of the MSLQ have been used independently of the entire metric elsewhere, and the self-efficacy subscale (abbreviated as the SE subscale for the remainder of the paper) has been used reliably in higher education science contexts (Hilpert, Stempien, van der Hoeven Kraft, \& Husman, 2013; Partin \& Haney, 2012).

In addition to the SE subscale, we chose to modify the Sources of Self-efficacy in Science Classrooms - Physics (SOSESC-P) instrument, an instrument with 33 Likert-style items anchored on five points (i.e., one = strongly disagree, five $=$ strongly agree) originally designed to assess changes in self-efficacy in undergraduate physics classrooms (Fencl \& Scheel, 2005). These items are analyzed as four subscales (i.e., vicarious learning, emotional arousal, social persuasion, performance accomplishment), capturing the facets of self-efficacy originally described by Bandura (1977). The instrument is scored by averaging student responses for all items and by calculating the average for student responses within each subscale (Fencl \& Scheel, 2005). We intended to use the overall score in our analysis but also examined the scores on each of the subscales to assess the validity of the metric. While the original metric specified 
that students respond to each item in the context of physics classes, we modified the metric wording to specify Anatomy and Physiology class as the context. We refer to this instrument as the SOSESC for the remainder of this paper.

To assess science identity, we used a selection of 12 Likert-style items, anchored on five points (i.e., zero $=$ not at all, four $=$ very much so), to assess students' personal identification as a science person (one item), recognition of science identity by their communities (three-item subscale), sense of competence when performing science tasks (five-item subscale), and their interest in science (three-item subscale) (Hazari et al., 2010). This instrument is scored by calculating the average of the items within each subscale, and then the subscale scores are averaged to create a science identity proxy variable (Wang \& Hazari, 2018). We refer to this assessment as the ID metric and describe the proxy variable as the ID score for the remainder of the paper.

Iterations of the ID metric have been used in studies examining persistence in undergraduate physics and engineering education and careers, and the construct validity of the subscales for assessing being a "physics person" or a "math person" has been confirmed using factor analyses (Cribbs et al., 2015; Godwin et al., 2016). For this study, we modified the item wording to ask students about being a "biology person," because anatomy and physiology topics fall within the domain of biology and require competency in using biological terminology. A\&P is an introductory biology course that contains advanced scientific language taught by biologists in our context, but it is designed for students who are not biology majors. Thus, the outcome of completing A\&P is not to be a biologist, but to apply biology knowledge in health contexts. We argue that the shared language and skills of these basic and applied sciences are rooted in biology, and so being a "biology person" may be an important negotiation for students to make to successfully develop the skills and knowledge they are expected to as part of successfully completing an A\&P course.

While the metrics in the pretest and posttest were identical (i.e., the SE subscale, SOSESC, and ID metric), the pretest also contained questions asking students to select undergraduate chemistry and biology courses they had already completed, as well as a question asking if they had taken a college-level introductory A\&P course previously. We consolidated student responses of taking either science majors or non-majors introductory chemistry or biology courses into two binary variables describing having taken chemistry or biology classes previously. Reporting that they were retaking A\&P was also a binary variable, regardless of if that attempt was at the present or a previous institution. At the end of the posttest, students were asked to report demographic information (i.e., gender, racial or ethnic heritage, major, and class).

All quantitative analyses were conducted using R (R Core Team, 2019, version 3.6.0). We utilized the lavaan (Rosseel, 2012) and sem (Fox, Nie, \& Byrnes, 2017) packages for factor and path analyses, the lm.beta package (Behrendt, 2014) for regression analysis, the ggplot2 (Wickham, 2016), GGally (Schloerke et al., 2016), and reshape2 (Wickham, 2007) packages to construct correlation matrices, and the psych package (Revelle, 2018) to conduct reliability analysis. We opted to use the larger pretest dataset $(n=83)$ for all analyses as opposed to the paired dataset because the low response rate on demographic questions precluded statistically powerful comparisons across demographic factors in our pilot models, and because paired pretest and posttest survey comparisons of all metrics were not statistically different. Further, our research questions did not seek to measure change over time, and so quantifying the relationship among factors measured at one time point was sufficient.

\subsection{Qualitative Data Collection and Analysis}

Semi-structured interviews were conducted by a member of the research team, who asked about each participant's decision to retake A\&P, their experiences of self-efficacy when completing challenging A\&P tasks, and their definitions and experiences of being a biology person. While we also asked about test-taking strategies as a potential angle to view self-efficacy, the responses from that question were linear and did not describe either science identity or self-efficacy, and so no major themes emerged from responses to those questions. The interviews were professionally transcribed prior to analysis. Pseudonyms were assigned to each interviewee. Two members of the research team iteratively read and coded the transcripts separately before coming together to discuss their codes, after which codes were consolidated and definitions were clarified. In phenomenology, themes emerge from the participants' narrative of their experiences and related emotions (Creswell, 2013), which are coded and described by the researchers. The transcripts were re-coded using this agreed-upon coding scheme, and this code/re-code strategy completed by at least two researchers bolsters the trustworthiness of our study by increasing the dependability of our methods. A third member of the research team acted as a peer debriefer to further refine the coding scheme until consensus was reached. Through the consensus of multiple researchers and a peer debriefer, we increased the credibility of our qualitative analysis, and as a mixed methods study, the quantitative data we collected are a source of triangulation, further bolstering the credibility and trustworthiness. By using purposive sampling, we addressed the transferability 
dimension of trustworthiness (Anney, 2015). Codes representing major themes were included in our final codebook, while concepts described less frequently by few participants were determined to be not characteristic of the phenomenon of retaking A\&P, and so they were removed from further analysis.

\section{Results}

\subsection{Validity and Reliability of Self-efficacy Metrics}

The prerequisite step to answering our quantitative research questions was to establish the validity and reliability of the instruments we used in our situated context (Dolan, 2015; Knekta, Runyon, \& Eddy, 2019). Because the SOSESC and ID metric had not been used in biology classrooms previously, we were especially interested in determining their validity in this context. Using Cronbach's alpha, we determined that both the SE subscale and the SOSESC measure were reliable in our context $(=0.96$ and $=0.93$, respectively); however, the individual subscales of the SOSESC did not all demonstrate reliability. The Performance Accomplishment $(=0.84)$ and Emotional Arousal $(=0.85)$ subscales demonstrated good reliability, though the Vicarious Learning $(=0.69)$ and Social Persuasion $(=0.64)$ subscales narrowly failed to meet the acceptable 0.70 threshold (P. Kline, 2000).

The SE subscale of the MSLQ has been used reliably in many settings, and other studies have demonstrated convergent and divergent validity comparing the SE subscale to other subscales within the MSLQ (Hilpert et al., 2013), indicating that it does not capture elements of the other learning strategies and student affect measured by other subscales of the MSLQ. As the SOSESC is a newer, less established metric, we investigated whether it demonstrated concurrent validity with the more-established SE subscale.

Correlations of SOSESC items with SE subscale items were weakly to moderately correlated $(r \leq 0.64)$ compared to correlations within the SE subscale alone, which were more highly correlated to each other $(0.57 \leq r \leq 0.85)$. While all items within the SE subscale were correlated with one another, fewer items were significantly correlated between the SOSESC and the SE subscale (60.6\% of pairwise correlations; see Supplementary Material). The Emotional Arousal and Performance Accomplishment subscales overall had more items that were significantly correlated with items on the SE subscale (75.0\% and $80.0 \%$, respectively) than did the Social Persuasion and Vicarious Learning subscales (23.2\% and $51.8 \%$, respectively). Because the items on the SOSESC did not demonstrate concurrent validity with items on the SE subscale, and because the SOSESC subscales had low reliability, we decided not to use participant responses on this metric in further analyses.

\subsection{Validity and Reliability of Science Identity Metric}

The ID metric had not been previously used in a biology context, but we found it to be reliable using Cronbach's alpha $(=0.96)$. Previous research and factor analyses in physics and mathematics contexts using this metric has resulted in a proposed four-factor model for science identity, with "Interest" and "Recognition" constructs regressing directly to "Science Identity" and serving as mediators between "Performance/Competence" and "Science Identity" (Cribbs et al., 2015; Godwin, Potvin, Hazari, \& Lock, 2013).

Though our sample size is smaller than the 200 recommended for factor analysis (R. Kline, 2005), the ID metric scored "marvelously" on a Kaiser-Meyer-Olkin test for sampling adequacy (KMO $=0.92)$. Therefore, to evaluate the structural validity of the subscales within the metric, we conducted a confirmatory factor analysis (CFA) on the model, accounting for multivariate non-normality using the robust "MLM" estimator (Rosseel, 2012). To test the efficacy of this model in our context, we chose to include the four fit indices recommended by Kline (2005): $\chi^{2}$, root mean square error of approximation (RMSEA), comparative fit index (CFI), and the standardized root mean square residual (SRMR).

Most of the paths identified in the original model were found to be significant in our analysis at the $p<.0001$ level, except for the regression of "Interest" to "Science Identity," which was not significant (Supplementary Figure 2). While the individual items fell satisfactorily within their constructs (Tabachnick \& Fidell, 2000; Supplementary Table 1), the model fit overall was poor. The SRMR approached an acceptable value to indicate a good fit, but none of the other fit indices fell into acceptable ranges (Hu \& Bentler, 1999, Supplementary Table 2). While we cannot make sweeping conclusions about the structural validity of this metric due to our sample size, these results offer a first step to explore how this metric is defined and used to describe science identity in biology contexts. The lack of a significant path between the constructs of "Interest" and "Science Identity" suggests that an alternative factor arrangement may be useful. While the structural validity of this metric in terms of the relationships between subscales was not aligned with previously published work in other contexts, each subscale loaded independently and contributed to overall science identity. 
To determine whether the composite score would be an appropriate science identity score for our analyses, we correlated the composite ID score with participant's response to the single science identity item ("I see myself as a biology person") to test the validity of the ID score (Hazari, Cass, \& Beattie, 2015). The single item and the ID score were highly correlated in a Pearson's correlation test $(r=0.92, p<.0001)$, suggesting that participant responses to the subscale items closely mirror their self-identification of being a biology person. We used the ID score in further analyses, as it still captured the overall construct of identity despite the unclear relationships between subscales within the metric.

\subsection{Relating Self-efficacy, Identity, and Course Outcomes}

After testing the reliability and validity of our data using these three instruments, we sought to clarify if science identity, self-efficacy, or college course preparation factors predict course outcomes (i.e., final course grade) for students enrolled in A\&P courses with hierarchical regression models. We also sought to explore differences in student self-efficacy and science identity between re-takers and first-timers.

We tested for normality using the Shapiro-Wilk test, which revealed that the SE score was normally distributed $(p$ $=.095)$, but the ID score and final grade were not $(p<.0001$ and $p=.002$, respectively). Using a two-sample t-test, we determined that there were no differences between re-takers and first-timers on the SE subscale $(t=-0.49, p=.630)$. A Wilcoxon Rank Sum Test revealed that students' ID scores did not differ based on their re-taker status $(W=797.5, p$ $=.690)$. Interestingly, when comparing final grade as a course outcome, re-takers $(M=82.09 \%)$ on average scored no differently than first-timers $(M=83.29 \% ; W=748, p=.942)$, despite having taken the course previously.

We created hierarchical regression models using prior college science coursework as potential predictor variables before adding SE and ID scores to the subsequent models. Prior coursework did not predict final grade in the first regression model (Model 1: $\mathrm{F}=0.97, \mathrm{df}=79, \mathrm{p}=.410$; Table 1 ). Next, we added SE score and ID score individually into two versions of a second model. Model 2-SE, including SE score, was significant $(\mathrm{F}=3.06, \mathrm{df}=78, p=.022)$, with SE score being a significant predictor $(p=.003$; Table 1$)$. The other variation of the second model, Model 2-ID, including ID score had greater explanatory power $(\mathrm{F}=3.66, \mathrm{df}=78, p=.009)$, with ID score being the significant predictor in the model $(p=.001$; Table 1). The third iteration of the model which added both SE and ID scores explained the most variance $(\mathrm{F}=3.39, \mathrm{df}=77, p=.008)$, but the significance of SE score as a predictor was lost, and ID score was the only significant predictor $(p=.043$; Table 1$)$.

Table 1. Results of Hierarchical Regression Analysis of College Science Prerequisites and Affect Scores Predicting Final Course Grade

\begin{tabular}{|c|c|c|c|c|c|c|c|c|}
\hline \multirow{2}{*}{$\begin{array}{l}\text { Predictor } \\
\text { Variables }\end{array}$} & \multicolumn{2}{|c|}{ Model 1} & \multicolumn{2}{|c|}{ Model 2-SE } & \multicolumn{2}{|c|}{ Model 2-ID } & \multicolumn{2}{|l|}{ Model 3} \\
\hline & $\beta$ & $\mathbf{t}$ & $\beta$ & $\mathbf{t}$ & $\beta$ & $\mathbf{t}$ & $\beta$ & $\mathbf{t}$ \\
\hline $\begin{array}{l}\text { Biology } \\
\text { Prerequisite }\end{array}$ & -0.158 & -1.409 & -0.126 & -1.172 & -0.185 & -1.745 & -0.159 & -1.493 \\
\hline $\begin{array}{l}\text { Chemistry } \\
\text { Prerequisite }\end{array}$ & 0.098 & 0.877 & 0.039 & 0.365 & -0.013 & -0.123 & -0.016 & -0.143 \\
\hline $\begin{array}{l}\text { Previous A\&P } \\
\text { Course }\end{array}$ & 0.081 & 0.719 & 0.037 & 0.343 & 0.081 & 0.759 & 0.056 & 0.524 \\
\hline SE score & & & 0.324 & $3.001 *$ & & & 0.184 & 1.457 \\
\hline ID score & & & & & 0.368 & $3.365^{* *}$ & 0.266 & $2.057 *$ \\
\hline$R^{2}$ & -0.001 & & $0.091 *$ & & $0.114^{* *}$ & & $0.127^{* *}$ & \\
\hline
\end{tabular}




\subsection{Qualitative Findings}

Our five interviewees had reported on the pretest survey that they were retaking A\&P after a previous enrollment at either their present or a previous institution. The interview topics probed the experiences of students retaking the class from a social cognitive theory lens, asking them to describe environmental and personal factors that they experienced in both enrollments, and to expand on their definition of a "biology person." In the analysis of interviewee responses, five major themes emerged, falling under identity (Table 2) or social cognitive (Table 3) factors. Our initial hypothesis was that students retaking A\&P may feel disconnected from science or have low academic self-efficacy, as prior academic failure can dampen students' self-efficacy (Ajjawi et al., 2020) and self-efficacy historically has been a positive predictor of course performance (Richardson, Abraham, \& Bond, 2012), but instead, our interviewees shared that they felt that they were biology people and their course performance did not reflect that truth about themselves.

Table 2. Emergent identity themes, definitions, and example quotes from interviewees, labeled by participant pseudonyms.

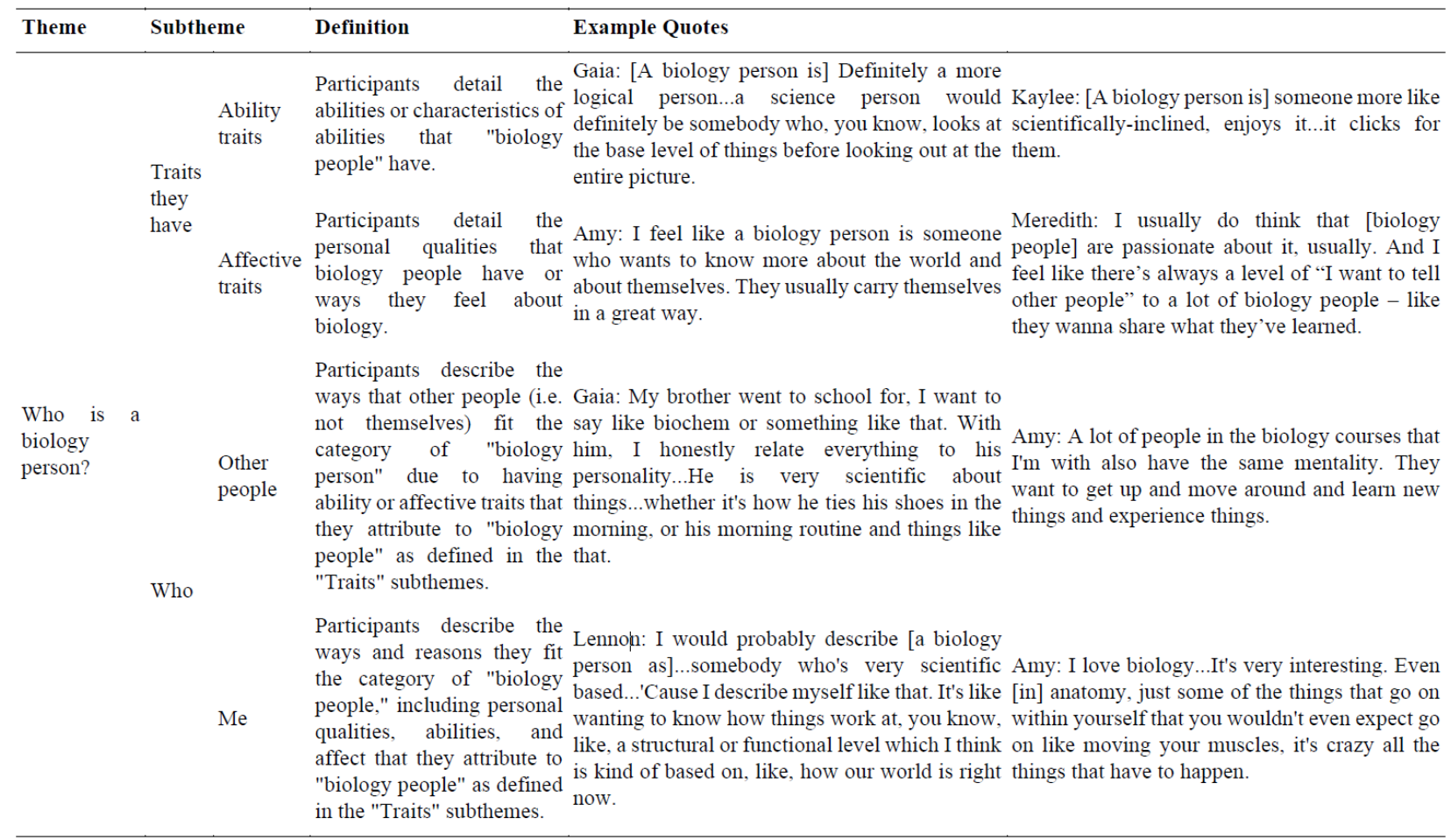


Table 2. Continued, Emergent identity themes, definitions, and example quotes from interviewees, labeled by participant pseudonyms.

\begin{tabular}{|c|c|c|c|c|}
\hline Theme & Subtheme & Definition & Example Quotes & \\
\hline \multirow{3}{*}{$\begin{array}{l}\text { Allied health } \\
\text { identity }\end{array}$} & $\begin{array}{l}\text { Perceptions } \\
\text { of allied } \\
\text { health } \\
\text { identities }\end{array}$ & $\begin{array}{l}\text { Participants describe their } \\
\text { perceptions of allied health } \\
\text { people and qualities of those with } \\
\text { allied health identities. }\end{array}$ & $\begin{array}{l}\text { Meredith: Just like, [nursing] is exciting, } \\
\text { because every day will be different, and } \\
\text { then it's just like you're actually doing } \\
\text { something good? And I just feel like } \\
\text { there's nothing bad about it, except for } \\
\text { like, the stress on your own self...it's just } \\
\text { exciting. You're part of this inner } \\
\text { community too, of people who are fine } \\
\text { with gross things and they're fine with } \\
\text { helping people. }\end{array}$ & $\begin{array}{l}\text { Lennon: I had a surgery that, like, } \\
\text { impacted my life. And the nurses that were } \\
\text { surrounding me, they were very } \\
\text { compassionate and they had a really good } \\
\text { bedside manner and so that was important } \\
\text { to me. I feel like it's a very rewarding } \\
\text { career. }\end{array}$ \\
\hline & $\begin{array}{l}\text { Practicing } \\
\text { allied health } \\
\text { identities }\end{array}$ & $\begin{array}{l}\text { Currently working within the } \\
\text { allied health community is an } \\
\text { important key for participants to } \\
\text { prepare for and be with people in } \\
\text { their desired careers. }\end{array}$ & $\begin{array}{l}\text { Amy: I'm very excited to begin the nursing } \\
\text { program. I always see nursing students in } \\
\text { their scrubs walking in the [nursing school } \\
\text { building] and I'm just so envious. I'm like, } \\
\text { "I wanna be them." }\end{array}$ & $\begin{array}{l}\text { Meredith: Um, and then I started, I like, } \\
\text { worked as like, or I still do, as a care } \\
\text { manager. And then I was like, "Oh my } \\
\text { gosh, yes!" And then it's like, wow, I wish } \\
\text { I could do more. }\end{array}$ \\
\hline & $\begin{array}{l}\text { Vision } \\
\text { career }\end{array}$ & $\begin{array}{l}\text { Participants describe vivid, } \\
\text { compelling career goals and the } \\
\text { reasons they chose to pursue } \\
\text { them }\end{array}$ & $\begin{array}{l}\text { Kaylee: My career goal is to be, eventually, } \\
\text { a NICU nurse. It's appealing 'cause, well, I } \\
\text { love science and I love kids so I kind of just } \\
\text { want something that's not the same all the } \\
\text { time or it's just also is like rewarding. }\end{array}$ & $\begin{array}{l}\text { Meredith: I've noticed like, a lot of nurses, } \\
\text { it's just like, "I wanna help people." And } \\
\text { it's like, "yeah, that's good, but can you do } \\
\text { this?" And, so, I think it's gonna be really } \\
\text { cool to take what I've learned and actually } \\
\text { use it, and be able to see it in a lab chart, or } \\
\text { be able to explain in my head like why this } \\
\text { may be happening in a person. }\end{array}$ \\
\hline $\begin{array}{l}\text { Identity is } \\
\text { practiced in } \\
\text { community }\end{array}$ & $\begin{array}{l}\text { Academic } \\
\text { community }\end{array}$ & $\begin{array}{l}\text { Students work together to } \\
\text { achieve their goals as biology } \\
\text { people and discuss seeking out } \\
\text { and interacting with their } \\
\text { academic community. While the } \\
\text { community is supportive, } \\
\text { students describe the competition } \\
\text { within it to secure spots in the } \\
\text { nursing program. }\end{array}$ & $\begin{array}{l}\text { Amy: Some of us are SES majors, which is } \\
\text { Sports and Exercise Science, and some of } \\
\text { us are nursing majors. We both have } \\
\text { different goals at the end, but currently } \\
\text { we're working towards the same thing, and } \\
\text { it's nice to feel like we're all focused } \\
\text { towards one goal. }\end{array}$ & $\begin{array}{l}\text { Meredith: I think with my friends, I } \\
\text { definitely identify as someone who's a } \\
\text { biology person. But with some of my other } \\
\text { peers, I feel, just from, like, competition, } \\
\text { sometimes I do not feel equal... [the } \\
\text { competition] makes people feel bad about } \\
\text { their knowledge and what they don't } \\
\text { know, or what they haven't done. }\end{array}$ \\
\hline
\end{tabular}

\subsubsection{Identity Themes}

When asked to describe who a "biology person" is, interviewees described biology people as having certain affect (e.g., confidence or enthusiasm) and abilities (e.g., critical thinking or logic; Table 2). Each participant reported being a biology person themselves, and they described being a biology person in both their lives and in other people's lives. The other people they described as being biology people were often friends or family members, but interestingly, participants did not mention teachers or authority figures as examples of biology people. While one participant, Amy, only described biology people as having affective traits, all other participants described both affective and ability traits relatively equally. Additionally, the total number of mentions that interviewees gave about each combination of "who" and "traits" of biology people was roughly equal (Table 4).

Table 4. Number of times an interviewee response was coded as a pair of subtheme under the "Who is a biology person?" theme.

\begin{tabular}{lccccc}
\hline Subtheme & Amy & Gaia & Kaylee & Lennon & Meredith \\
\hline Me/Affect & 3 & 3 & 2 & 1 & 2 \\
Me/Ability & 0 & 3 & 3 & 2 & 4 \\
Others/Affect & 2 & 1 & 1 & 2 & 4 \\
Others/Ability & 0 & 5 & 1 & 1 & 4
\end{tabular}

Interviewees often described allied health identities when asked to describe their goals in taking and retaking A\&P, including their perceptions of being in those careers, their participation in health care systems, and their career visions (Table 2). Within these descriptions, it is evident that these careers are desirable - desirable enough for students to endure a second or third time to retake a course for another chance to enter that career. Additionally, our interviewees 
recognized that they were not alone in their aims; other members of their academic community, while not always wishing to enter the same profession as them, were both supporters and competitors. While they banded together to learn the material, the competition to secure a place in the nursing program left some interviewees feeling insecure about their chances of achieving their goals, even though they so strongly identified with those goals (Table 2).

Table 3. Emergent social cognitive themes, definitions, and quotes from interviewees, labeled by participant pseudonyms.

\begin{tabular}{|c|c|c|c|c|}
\hline Theme & Subtheme & Definition & Example Quotes & \\
\hline \multirow{2}{*}{$\begin{array}{l}\text { The role of } \\
\text { the academic } \\
\text { environment }\end{array}$} & $\begin{array}{l}\text { Mismatch of } \\
\text { their } \\
\text { expectations } \\
\text { and what they } \\
\text { perceive to be } \\
\text { expected of } \\
\text { them }\end{array}$ & $\begin{array}{l}\text { Participants describe frustration } \\
\text { when they are not appropriately } \\
\text { recognized for what they know on } \\
\text { exams or by instructors. The } \\
\text { mismatch between what students } \\
\text { feel are fair expectations and what is } \\
\text { assessed threatens their legitimacy of } \\
\text { being a biology person. }\end{array}$ & $\begin{array}{l}\text { Gaia: I think it's just with A\&P in particular, } \\
\text { I'm very interested, but sometimes that just } \\
\text { doesn't show necessarily in my grades... [I am] } \\
\text { definitely more of a big picture science person, } \\
\text { so the entire body rather than just the small } \\
\text { details of it. }\end{array}$ & $\begin{array}{l}\text { Lennon: As the course of the semester went } \\
\text { on, I honestly feel like it's [become] a little } \\
\text { bit resentful, 'cause a lot of the people who I } \\
\text { have studied with, and I've even gone to } \\
\text { tutoring, will spend like two and a- half, } \\
\text { three weeks studying for this [exam], trying } \\
\text { to power through it and then... the test scores } \\
\text { aren't what we hoped it would be. }\end{array}$ \\
\hline & $\begin{array}{l}\text { Relevance of } \\
\text { content }\end{array}$ & $\begin{array}{l}\text { Participants relate how A\&P course } \\
\text { content has varying degrees of } \\
\text { relevance to their career and } \\
\text { academic goals, which influences } \\
\text { both their motivations and abilities to } \\
\text { learn it. }\end{array}$ & $\begin{array}{l}\text { Meredith: I think when you look at [it from] } \\
\text { afar, you're like, "This is too stupid"...But then } \\
\text { when you actually think about it, the questions } \\
\text { you're gonna have [to] ask yourself, as a nurse, } \\
\text { you realize, oh, it's [the] little things...So you } \\
\text { realize it's important but while you're taking } \\
\text { the class it just seems...really overwhelming. } \\
\text { It's like you're never gonna need to use this } \\
\text { information. }\end{array}$ & $\begin{array}{l}\text { Amy: I was a CNA for a year and I currently } \\
\text { work as a med tech. And to learn about these } \\
\text { things that go on within your body and to } \\
\text { actually experience it in like a clinical } \\
\text { setting. It's easier to relate back to course } \\
\text { work. }\end{array}$ \\
\hline \multirow[b]{2}{*}{$\begin{array}{l}\text { The role of } \\
\text { people in } \\
\text { their success }\end{array}$} & $\begin{array}{l}\text { Attribution } \\
\text { Theory }\end{array}$ & $\begin{array}{l}\text { Participants comment on areas } \\
\text { within their own locus of control and } \\
\text { external to their locus of control that } \\
\text { influence their performance and } \\
\text { success in the class. }\end{array}$ & $\begin{array}{l}\text { Gaia: I definitely really value, um, having just, } \\
\text { you know, a lot of open communication with } \\
\text { my professors just so I know, "Hey, you're } \\
\text { concerned with my success and so am I." }\end{array}$ & $\begin{array}{l}\text { Lennon: When there's an engaging } \\
\text { environment, I feel [more] obligated to } \\
\text { engage...outside of class than when it's a } \\
\text { non-engaging environment...[my] want to } \\
\text { participate is declining, I guess, due to the } \\
\text { environment. }\end{array}$ \\
\hline & Mindset & $\begin{array}{l}\text { Participants speak from a place of } \\
\text { growth mindset (they can achieve } \\
\text { difficult things even after failure) or } \\
\text { fixed mindset (they are helpless to } \\
\text { change their circumstances after } \\
\text { failure) (Dweck, 2000). }\end{array}$ & $\begin{array}{l}\text { Gaia: I just need this confidence...if I get a bad } \\
\text { grade I'll [sometimes tell myself], "Oh, you're } \\
\text { not good at this. You know, like come on..." } \\
\text { [I'm] doubting [myself] and [my] self-efficacy } \\
\text { and things like that. So, [instead I] definitely } \\
\text { talk myself through it and say, "Hey, okay, this } \\
\text { is why you missed it. Here's what we could do } \\
\text { next time. Just learn from your mistakes and } \\
\text { then continue on to the next test." }\end{array}$ & $\begin{array}{l}\text { Lennon: I feel great going into [the test]. And } \\
\text { then if I don't know, like the first question, } \\
\text { I'm like dead inside. Like it kinda like } \\
\text { crushes me a little bit... I'm like "Oh, I'm } \\
\text { gonna fail again because I've- I flopped...no } \\
\text { matter how hard I try, this is gonna happen." }\end{array}$ \\
\hline
\end{tabular}

\subsubsection{Social Cognitive Themes}

While one of our initial aims was to explore students' self-efficacy, the experiences interviewees described reflected other constructs within social cognitive theory, notably causal attributions and self-regulation (Eccles \& Wigfield, 2002). First, our participants described the role of their academic environment presented to them that they, as self-identified biology people, needed to navigate through (Table 3). Each student needed to retake the course to move forward in their programs, but when asked about their prior experiences with A\&P and their current enrollment, interviewees described a mismatch of expectations in assessment and course content. While some parts of what students were learning seemed immediately relevant to their current or future jobs, other topics, especially the finer details, seemed like an overwhelming amount of information to digest for the little value they perceived that it may have in their future.

Our second social cognitive theme describes the role of people in their success. While each interviewee reported similar experiences of being a biology person, they diverged in their descriptions of the power others had in their academic success. Subthemes under the role of people in their success describe the attributions and mindsets rather than their own self-efficacy, but interviewees diverged on how they attributed their performance in both enrollments and what types of mindset (i.e., fixed or growth) they maintained during their current enrollment. Gaia and Lennon epitomized this dichotomy; while Gaia reported collaboration between herself and the instructor, Lennon attributed performance primarily on the type of environment her instructors created. Both Gaia and Lennon described having test anxiety, but while Gaia demonstrated growth mindset in her approach to exams, Lennon described feelings of defeat after encountering questions to which she did not know the answer (Table 3). 


\section{Discussion}

\subsection{Affect Predicts Course Outcomes}

In our sample, having taken an undergraduate chemistry or biology course previously did not predict course grade in this A\&P context; however, previous work suggests that the quantity of prior experience in undergraduate science courses (Harris et al., 2004) and high school science experiences (Gultice et al., 2015) do improve final grade in A\&P classes. Our findings regarding the predictive value of taking prerequisite courses bolster the argument that prerequisite courses in higher education science settings may not predict outcomes in future science classes (Wright, Cotner, \& Winkel, 2009) and may not support students without proper curricular alignment along their educational pathways (Shaffer et al., 2016).

Our findings from the hierarchical regression models indicate that, in our best model, Model 3, ID score is the only significant predictor, but this model offers only negligible improvement on the predictive power of course grade when compared to the two versions of Model 2, with ID score and SE score added independently ( $<5 \%$ improvement in variance explained; Table 1). The single-affect models performed similarly well, yet the Model 2-ID minimally explained more variance of the two; this indicates that while self-efficacy and science identity are important predictors of A\&P performance, science identity may be slightly better. As examining science identity in A\&P contexts is a novel contribution, our results suggest that investigations of this construct are appropriate to inform future research and pedagogy.

The loss of significance of self-efficacy as a predictor to course outcomes when in a combined model with science identity is notable. A host of research described in a systematic literature review supports the use of self-efficacy - as measured by the same self-efficacy metric we used in our analyses (i.e., the self-efficacy subscale from the MSLQ; Pintrich et al., 1993) - above other self-regulated learning constructs as a predictor of tertiary Grade Point Average (GPA; Richardson et al., 2012); though, these studies did not include any disciplinary identities as potential predictors. Additionally, our study examined academic performance in only one undergraduate class instead of cumulative GPA of students. Further, as self-efficacy is a construct situated within domains and tasks (Bandura, 1986), academic self-efficacy may not be the only type of self-efficacy students have when engaging with A\&P. Other work that has observed that self-efficacy is not always the best predictor of narrower academic outcomes, such as exam grade, where previous academic performance is a better predictor (Ainscough et al., 2016).

Science identity as a predictor of a short-term academic outcome, such as final grade, is a novel finding in this study. Previous research has demonstrated that adolescent student participation in formal and informal science activities can be predicted by science identity (Vincent-Ruz \& Schunn, 2018). Indeed, the long-term summation of these choices is associated with graduate study and career choice, which undergraduate students' sense of science identity predicts (Estrada, Woodcock, Hernandez, \& Schultz, 2011; Hazari, Sadler, \& Sonnert, 2013). While studies investigating science identity have shown intricate trajectories of science identity in relation to persistence and career pursuit throughout students' undergraduate careers (Jackson \& Seiler, 2013; Robinson, Perez, Nuttall, Roseth, \& Linnenbrink-Garcia, 2018), our findings suggest assessing students' science identity also has utility for predicting short-term academic goal achievement.

\subsection{Re-takers and First-timers do not Perform Differently}

Our findings indicate that while affect can predict academic outcomes in A\&P, re-takers and first-timers do not differ in affect nor academic course outcomes. In our study, re-takers did not differ from first-timers in final grade, which is inconsistent with prior findings comparing first-timers and re-takers in A\&P contexts that suggest that first-timers tend to perform better than re-takers (Schutte, 2016), though our sample had a higher ratio of re-takers to first-timers than previous work, perhaps mathematically diluting the differences between the two groups. Additionally, out of all re-takers in our sample, $41 \%$ received the same or lower letter grade than the letter grade they reported from their previous attempt, in line with some work that suggests that prior anatomy coursework does not significantly benefit undergraduate students (Wehrman et al., 2020), but in contrast with other research which suggests that prior exposure to A\&P or retaking the course has a positive impact on student assessment grades (Schutte, 2016). Variance in re-taker success could be due to engagement in formative assessments, as prior research suggests that re-takers who complete formative assessments fare better than those who do not (Dibbs, 2019; Holland, Clarke, \& Glynn, 2016). Though we did not examine types of engagement quantitatively, one participant, Lennon, reported her difficulty staying engaged in the course during her second enrollment (Table 3). Interventions encouraging the completion of formative assessments may be an additional support re-takers would benefit from in A\&P contexts.

Potentially poor-achieving students who opt not to retake the class may have lower self-efficacy or science identity than those who return and try again, and thus those students would not appear in our sample. We were initially 
surprised that our interviewees, all taking the class for a second or third time, reported that they were biology people, despite needing remediation. The disaffect they felt was not in their own performance, as Ajjawi et al. (2020) reports, but rather in the course itself. It could be that re-takers have negative perceptions of the course but not low general self-efficacy, similarly to results of a study in chemistry education (Reardon, Traverse, Feakes, Gibbs, \& Rohde, 2010). Indeed, this type of frustration with instruction or perceived relevance of content may predict academic outcomes (Wilde, 2012), and in undergraduate anatomy contexts, student expectations of the course may aid their development of favorable perceptions of learning in the course (Anderton, Chiu, \& Aulfrey, 2016; Entezari \& Javdan, 2016).

\subsection{Re-takers Describe Themselves as Biology People}

Though we coded the interviews using an emergent coding scheme, interest in biology as an affective trait of biology people thematically overlapped with the theoretical model behind the ID metric. The "Recognition" subconstruct within science identity also overlapped with the theoretical model and interviewees' experiences, as the mismatch of our interviewees' expectations and the grades they received in their previous and current enrollment speaks to their sense of a lack of recognition. When participating in science activities, recognition from faculty (Thompson \& Jensen-Ryan, 2018) and peers (Le, Doughty, Thompson, \& Hartley, 2019) supports students' science identity development in undergraduate biology contexts, but perhaps the importance of recognition extends beyond the affirmation of science practices to the affirmation of academic practices. Participants reported practicing allied health careers through their jobs as certified nursing assistants, which illuminates a way they may perform their science identities in a competent way. While performance and competence beliefs cannot predict science identities apart from interest and recognition (Godwin et al., 2016), this finding suggests that active participation as health care professionals-in-training may be an expression of being a biology person. Previously, Carlone and Johnson (2007) described science identities of biology graduate students pursuing health care careers as being altruistic science identities as opposed to research science identities, and our findings suggest that undergraduate non-biology majors may similarly embody altruistic science identities. Future work is needed to parse out the convergence and divergence of biology and allied health identities.

We were initially perplexed about the lack of interviewee discussion of self-efficacy as part of their experience retaking the course. Though no question in our protocol explicitly asked interviewees to reflect on their confidence, when asked about their performance in A\&P, they described attributions and mindset, which both fall within social cognitive theory. Indeed, considering that self-efficacy is overshadowed by science identity in our regression models, we posit that science identity is a greater contributor to persistence for all students in A\&P courses. This aligns with findings from Estrada et al. (2011) that suggest that persistence is not weighted in some students' confidence of their ability, but rather rooted in their sense of belonging and identity within science communities.

\section{Limitations and Conclusions}

While previous work highlights problems with retention and remediation within A\&P courses (Gultice et al., 2015), much evidence that exists about A\&P attrition and retention is anecdotal or highly contextual, and further investigation is warranted to define the scope of this issue. Our study is similarly contextual and limited in that it occurred over one semester with a homogeneous population of students; thus, we were unable to look at potential demographic effects reported elsewhere, such as gender (Schutte, 2016; Vitali et al., 2020). Our use of final course grade as a proxy for academic success in our regression models is another limitation, as course grade does not necessarily capture student learning, but instead is only one facet of academic success (Schinske \& Tanner, 2014). Additionally, while the fact that our interviewees strongly identified as biology people initially surprised us, this could be partially explained by self-selection bias. Not all students who remediate may feel like biology people, and not all students who become part of the DFW statistic come back to take the course again. Furthermore, as we did not interview first-timers, we cannot describe the science identity experiences and expressions of those enrolled in A\&P for the first time.

Structurally, it would benefit both students and institutions to define what is important for nursing and allied health students to know so curricula could be framed as relevant to students' flourishing allied health identities. Given our findings about the perceived mismatch of what students expected to learn and what was relevant to their professional development, it would be beneficial to systematically investigate which topics students see as unimportant and develop pedagogical methods to frame those topics in a more explicitly relevant way. Additionally, soliciting student feedback about the relevance and familiarity of content both within A\&P and in introductory science courses may better prepare students and improve attitudes about these courses (Sato et al., 2017).

Future work in A\&P contexts is needed to identify additional factors relating to student success in these courses and how to support students in these contexts. From the lens of social cognitive theory and other expectancy/value theories, it would be beneficial to examine these intersections and self-regulated learning in A\&P. These investigations could 
help design interventions meant to support learning outcomes in A\&P; intervening during this biology prerequisite courses could benefit students' learning of their current coursework and further along in their programs as well (Brown, White, \& Power, 2017; McVicar et al., 2015).

The role of science identity warrants further study, especially investigating the structural validity of existing science identity metrics in biology contexts. Additionally, it would also be beneficial to explore further what a biology person is in relation to allied health identities. Our findings suggest that science identity is relevant to A\&P students, and so capturing who students believe themselves to be and to which communities they feel that they belong may be an efficacious avenue for motivating and retaining students. In this way, science identity may be leveraged in the future to better build learning communities to support academic and learning outcomes for A\&P students.

\section{References}

Ainscough, L., Foulis, E., Colthorpe, K., Zimbardi, K., Robertson-Dean, M., Chunduri, P., \& Lluka, L. (2016). Changes in Biology Self-Efficacy during a First-Year University Course. CBE Life Sciences Education, 15(2), ar19. https://doi.org/10.1187/cbe.15-04-0092

Ajjawi, R., Dracup, M., Zacharias, N., Bennett, S., \& Boud, D. (2020). Persisting students' explanations of and emotional responses to academic failure. Higher Education Research \& Development, 39(2), 185-199. https://doi.org/10.1080/07294360.2019.1664999

Anderton, R. S., Chiu, L. S., \& Aulfrey, S. (2016). Student Perceptions to Teaching Undergraduate Anatomy in Health Sciences. International Journal of Higher Education, 5(3), 201-216. https://doi.org/10.5430/ijhe.v5n3p201

Anderton, R. S., Evans, T., \& Chivers, P. T. (2016). Predicting Academic Success of Health Science Students for First Year Anatomy and Physiology. International Journal of Higher Education, 5(1), 250-260. https://doi.org/10.5430/ijhe.v5n1p250

Andrew, S. (1998). Self-efficacy as a predictor of academic performance in science. Journal of Advanced Nursing, 27(3), 596-603. https://doi.org/10.1046/j.1365-2648.1998.00550.x

Anney, V. N. (2015). Ensuring the Quality of the Findings of Qualitative Research: Looking at Trustworthiness Criteria. Journal of Emerging Trends in Educational Research and Policy Studies (JETERAPS), 5(2), 272-281.

Bandura, A. (1977). Self-efficacy: Toward a unifying theory of behavioral change. Psychological Review, 84(2), 191-215. https://doi.org/10.1037/0033-295X.84.2.191

Bandura, A. (1986). Social foundations of thought and action: A social cognitive theory. Englewood Cliffs, NJ: Prentice-Hall.

Bandura, A. (1997). Self-efficacy: The exercise of control. New York, NY: Freeman.

Behrendt, S. (2014). Im.beta: Add Standardized Regression Coefficients to lm-Objects.

Brown, S. J. J., White, S., \& Power, N. (2017). Introductory anatomy and physiology in an undergraduate nursing curriculum. Advances in Physiology Education, 41(1), 56-61. https://doi.org/10.1152/advan.00112.2016

Caon, M., \& Treagust, D. (1993). Why Do Some Nursing Students Find Their Science Courses Difficult? Journal of Nursing Education, 32(6), 255-259. https://doi.org/10.3928/0148-4834-19930601-07

Carlone, H. B., \& Johnson, A. (2007). Understanding the science experiences of successful women of color: Science identity as an analytic lens. Journal of Research in Science Teaching, 44(8), 1187-1218. https://doi.org/10.1002/tea.20237

Creswell, J. (2013). Qualitative inquiry and research design: Choosing among five approaches (3rd ed.). Thousand Oaks, California: SAGE Publications.

Cribbs, J. D., Hazari, Z., Sonnert, G., \& Sadler, P. M. (2015). Establishing an Explanatory Model for Mathematics Identity. Child Development, 86(4), 1048-1062. https://doi.org/10.1111/cdev.12363

Dibbs, R. (2019). Forged in failure: engagement patterns for successful students repeating calculus. Educational Studies in Mathematics, 101, 35-50. https://doi.org/10.1007/s10649-019-9877-0

Dolan, E. L. (2015). Biology education research 2.0. CBE Life Sciences Education, 14(4), ed1. https://doi.org/10.1187/cbe.15-11-0229

Dweck, C. S. (2000). Self-theories: Their role in motivation, personality, and development. Philadelphia, PA: 
Psychology Press.

Eccles, J. S., \& Wigfield, A. (2002). Motivational Veliefs, Values, and Goals. Annu. Rev. Psychol., 53, 109-132. https://doi.org/10.1146/annurev.psych.53.100901.135153

Entezari, M., \& Javdan, M. (2016). Active Learning and Flipped Classroom, Hand in Hand Approach to Improve Students Learning in Human Anatomy and Physiology. International Journal of Higher Education, 5(4), 222-231. https://doi.org/10.5430/ijhe.v5n4p222

Estrada, M., Woodcock, A., Hernandez, P. R., \& Schultz, P. W. (2011). Toward a Model of Social Influence That Explains Minority Student Integration into the Scientific Community. Journal of Educational Psychology, 103(1), 206-222. https://doi.org/10.1037/a0020743

Fencl, H., \& Scheel, K. (2005). Engaging Students: An Examination of the Effects of Teaching Strategies on Self-Efficacy and Course Climate in a Nonmajors Physics Course. Journal of College Science Teaching, 35(1), 20-24.

Flowers, A. M., \& Banda, R. (2016). Cultivating science identity through sources of self-efficacy. Journal for Multicultural Education, 10(3), 405-417. https://doi.org/10.1108/JME-01-2016-0014

Fox, J., Nie, Z., \& Byrnes, J. (2017). sem: Structural Equation Models. Retrieved from https://cran.r-project.org/package=sem

Godwin, A., Potvin, G., Hazari, Z., \& Lock, R. (2013). Understanding engineering identity through structural equation modeling. Proceedings - Frontiers in Education Conference, FIE, 50-56. https://doi.org/10.1109/FIE.2013.6684787

Godwin, A., Potvin, G., Hazari, Z., \& Lock, R. (2016). Identity, Critical Agency, and Engineering: An Affective Model for Predicting Engineering as a Career Choice. Journal of Engineering Education, 105(2), 312-340. https://doi.org/10.1002/jee.20118

Goradia, T., \& Bugarcic, A. (2019). Exploration and evaluation of the tools used to identify first year at-risk students in health science courses: A systematic review. Advances in Integrative Medicine, 6(4), 143-150. https://doi.org/10.1016/j.aimed.2018.11.003

Griff, E. R. (2016). Changing undergraduate human anatomy and physiology laboratories: perspectives from a large-enrollment course. Advances in Physiology Education, 40(3), 388-392. https://doi.org/10.1152/advan.00057.2016

Gultice, A., Witham, A., \& Kallmeyer, R. (2015). Are your students ready for anatomy and physiology? Developing tools to identify students at risk for failure. Advances in Physiology Education, 39(2), 108-115. https://doi.org/10.1152/advan.00112.2014

Harris, D. E., Hannum, L., \& Gupta, S. (2004). Contributing Factors to Student Success in Anatomy \& Physiology: Lower Outside Workload \& Better Preparation. The American Biology Teacher, 66(3), 168-175. https://doi.org/10.2307/4451650

Hazari, Z., Cass, C., \& Beattie, C. (2015). Obscuring power structures in the physics classroom: Linking teacher positioning, student engagement, and physics identity development. Journal of Research in Science Teaching, 52(6), 735-762. https://doi.org/10.1002/tea.21214

Hazari, Z., Sadler, P. M., \& Sonnert, G. (2013). The Science Identity of College Students: Exploring the Intersection of Gender, Race, and Ethnicity. Journal of College Science Teaching, 42(5), 82-91.

Hazari, Z., Sonnert, G., Sadler, P. M., \& Shanahan, M.-C. (2010). Connecting high school physics experiences, outcome expectations, physics identity, and physics career choice: A gender study. Journal of Research in Science Teaching, 47(8), 978-1003. https://doi.org/10.1002/tea.20363

Hilpert, J. C., Stempien, J., van der Hoeven Kraft, K. J., \& Husman, J. (2013). Evidence for the Latent Factor Structure of the MSLQ: A New Conceptualization of an Established Questionnaire. SAGE Open, 3(4), 1-10. https://doi.org/10.1177/2158244013510305

Holland, J., Clarke, E., \& Glynn, M. (2016). Out of sight, out of mind: Do repeating students overlook online course components? Anatomical Sciences Education, 9(6), 555-564. https://doi.org/10.1002/ase.1613

Hu, L. T., \& Bentler, P. M. (1999). Cutoff criteria for fit indexes in covariance structure analysis: Conventional criteria versus new alternatives. Structural Equation Modeling, 6(1), 1-55. 
https://doi.org/10.1080/10705519909540118

Jackson, P. A., \& Seiler, G. (2013). Science identity trajectories of latecomers to science in college. Journal of Research in Science Teaching, 50(7), 826-857. https://doi.org/10.1002/tea.21088

Kline, P. (2000). The handbook of psychological testing (2nd ed.). London: Routledge.

Kline, R. (2005). Principles and practice of structural equation modeling (2nd ed.). New York, NY: Guilford.

Knekta, E., Runyon, C., \& Eddy, S. (2019). One Size Doesn't Fit All: Using Factor Analysis to Gather Validity Evidence When Using Surveys in Your Research. CBE Life Sciences Education, 18(1), rm1. https://doi.org/10.1187/cbe.18-04-0064

Le, P. T., Doughty, L., Thompson, A. N., \& Hartley, L. M. (2019). Investigating undergraduate biology students' science identity production. CBE Life Sciences Education, 18(4), ar50. https://doi.org/10.1187/cbe.18-10-0204

Liu, J. X., Goryakin, Y., Maeda, A., Bruckner, T., \& Scheffler, R. (2017). Global Health Workforce Labor Market Projections for 2030. Human Resources for Health, 15(1), 11. https://doi.org/10.1186/s12960-017-0187-2

McVicar, A., Andrew, S., \& Kemble, R. (2015). The 'bioscience problem' for nursing students: An integrative review of published evaluations of Year 1 bioscience, and proposed directions for curriculum development. Nurse Education Today, 35(3), 500-509. https://doi.org/10.1016/j.nedt.2014.11.003

Moustakas, C. E. (1994). Phenomenological research methods. Thousand Oaks, California: SAGE. https://doi.org/10.4135/9781412995658

Partin, M. L., \& Haney, J. J. (2012). The CLEM model: Path analysis of the mediating effects of attitudes and motivational beliefs on the relationship between perceived learning environment and course performance in an undergraduate non-major biology course. Learning Environments Research, 15(1), 103-123. https://doi.org/10.1007/s10984-012-9102-x

Pintrich, P. R., Smith, D. A. F., Garcia, T., \& McKeachie, W. J. (1993). Reliability and Predictive Validity of the Motivated Strategies for Learning Questionnaire (MSLQ). Educational and Psychological Measurement, 53(3), 801-813. https://doi.org/10.1177/0013164493053003024

R Core Team. (2019). R: A Language and Environment for Statistical Computing. Vienna, Austria: R Foundation for Statistical Computing. Retrieved from https://www.r-project.org

Reardon, R. F., Traverse, M. A., Feakes, D. A., Gibbs, K. A., \& Rohde, R. E. (2010). Discovering the determinants of chemistry course perceptions in undergraduate students. Journal of Chemical Education, 87(6), 643-646. https://doi.org/10.1021/ed100198r

Revelle, W. (2018). psych: Procedures for Psychological, Psychometric, and Personality Research. Evanston, Illinois: Northwestern University.

Richardson, M., Abraham, C., \& Bond, R. (2012). Psychological correlates of university students' academic performance: A systematic review and meta-analysis. Psychological Bulletin, 138(2), 353-387. https://doi.org/10.1037/a0026838

Robinson, K. A., Perez, T., Nuttall, A. K., Roseth, C. J., \& Linnenbrink-Garcia, L. (2018). From Science Student to Scientist: Predictors and Outcomes of Heterogeneous Science Identity Trajectories in College. Developmental Psychology, 54(10), 1977-1992. https://doi.org/10.1037/dev0000567

Rosseel, Y. (2012). lavaan: An R Package for Structural Equation Modeling. Journal of Statistical Software, 48(2), 1-36. https://doi.org/10.18637/jss.v048.i02

Sato, B. K., Lee, A. K., Alam, U., Dang, J. V., Dacanay, S. J., Morgado, P., .. Sandholtz, J. H. (2017). What's in a Prerequisite? A Mixed-Methods Approach to Identifying the Impact of a Prerequisite Course. CBE Life Sciences Education, 16(1), ar16. https://doi.org/10.1187/cbe.16-08-0260

Schinske, J., \& Tanner, K. (2014). Teaching More by Grading Less (or Differently). CBE Life Sciences Education, 13, 159-166. https://doi.org/10.1187/cbe.cbe-14-03-0054

Schloerke, B., Crowley, J., Cook, D., Briatte, F., Marbach, M., Thoen, E., ... Larmarange, J. (2016). GGally: Extension to "ggplot2."

Schutte, A. F. (2016). Who is repeating anatomy? Trends in an undergraduate anatomy course. Anatomical Sciences Education, 9(2), 171-178. https://doi.org/10.1002/ase.1553 
Shaffer, J. F., Dang, J. V., Lee, A. K., Dacanay, S. J., Alam, U., Wong, H. Y., ... Sato, B. K. (2016). A familiar(ity) problem: Assessing the impact of prerequisites and content familiarity on student learning. PLOS ONE, 11(1), e0148051. https://doi.org/10.1371/journal.pone.0148051

Slominski, T., Grindberg, S., \& Momsen, J. (2019). Physiology is hard: a replication study of students' perceived learning difficulties. Advances in Physiology Education, 43(2), 121-127. https://doi.org/10.1152/advan.00040.2018

Sturges, D., \& Maurer, T. (2013). Allied Health Students' Perceptions of Class Difficulty: The Case of Undergraduate Human Anatomy and Physiology Classes. The Internet Journal of Allied Health Sciences and Practice, 11(4).

Tabachnick, B. G., \& Fidell, L. (2000). Using multivariate statistics (4th ed.). Boston, MA: Allyn \& Bacon.

Thompson, J. J., \& Jensen-Ryan, D. (2018). Becoming a "science person": Faculty recognition and the development of cultural capital in the context of undergraduate biology research. CBE Life Sciences Education, 17(4). https://doi.org/10.1187/cbe.17-11-0229

Trujillo, G., \& Tanner, K. D. (2014). Considering the Role of Affect in Learning: Monitoring Students' Self-Efficacy, Sense of Belonging, and Science Identity. CBE Life Sciences Education, 13(1), 6-15. https://doi.org/10.1187/cbe.13-12-0241

Vincent-Ruz, P., \& Schunn, C. D. (2018). The nature of science identity and its role as the driver of student choices. International Journal of STEM Education, 5(1), 1-12. https://doi.org/10.1186/s40594-018-0140-5

Vitali, J., Blackmore, C., Mortazavi, S., \& Anderton, R. (2020). Tertiary Anatomy and Physiology, A Barrier for Student Success. International Journal of Higher Education, 9(2), 289-296. https://doi.org/10.5430/ijhe.v9n2p289

Wang, J., \& Hazari, Z. (2018). Promoting high school students' physics identity through explicit and implicit recognition. Physical Review Physics Education Research, 14(2), 20111. https://doi.org/10.1103/PhysRevPhysEducRes.14.020111

Wehrman, G., Ryan, K., \& Auerbach, B. (2020). Effects of Prior Anatomy Coursework on Assessment Performance and Study Habits. The FASEB Journal, 34(S1), 1-1. https://doi.org/10.1096/fasebj.2020.34.s1.03011

Wickham, H. (2007). Reshaping Data with the reshape Package. Journal of Statistical Software, 21(12), 1-20. https://doi.org/10.18637/jss.v021.i12

Wickham, H. (2016). ggplot2: Elegant Graphics for Data Analysis. Springer-Verlag New York. https://doi.org/10.1007/978-3-319-24277-4_9

Wilde, J. (2012). The Relationship between Frustration Intolerance and Academic Achievement in College. International Journal of Higher Education, 1(2), 1-8. https://doi.org/10.5430/ijhe.v1n2p1

Wright, R., Cotner, S., \& Winkel, A. (2009). Minimal Impact of Organic Chemistry Prerequisite on Student Performance in Introductory Biochemistry. CBE Life Sciences Education, 8(1), 44-54. https://doi.org/10.1187/cbe.07-10-0093

Zimmerman, B. J. (2000). Self-Efficacy: An Essential Motive to Learn. Contemporary Educational Psychology, 25, 82-91. https://doi.org/10.1006/ceps.1999.1016 


\section{Supplementary Material}

A.

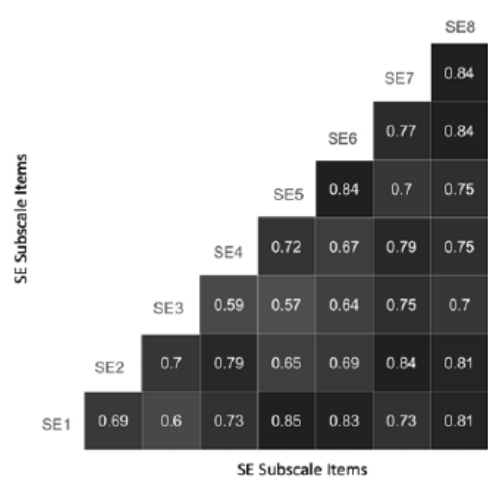

$\begin{array}{ll}\text { Legend: } r & 1.0 \\ \text { values as } & 0.5 \\ \text { heatmap } & 0.0 \\ \text { saturation } & -0.5 \\ & -1.0\end{array}$
B.

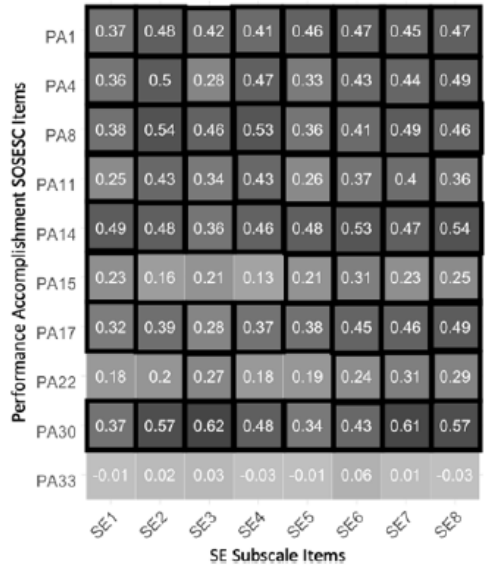

D.

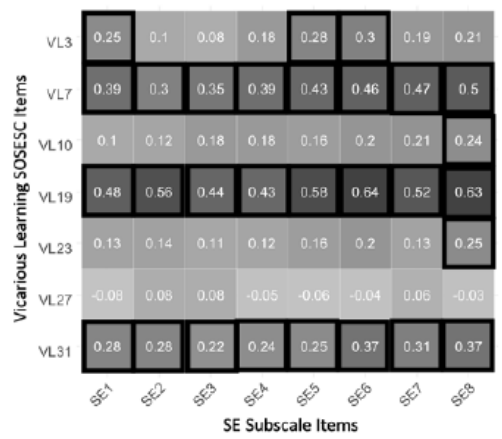

C.

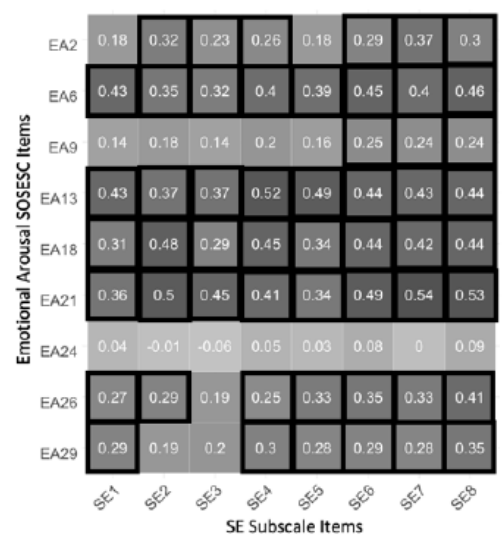

E.

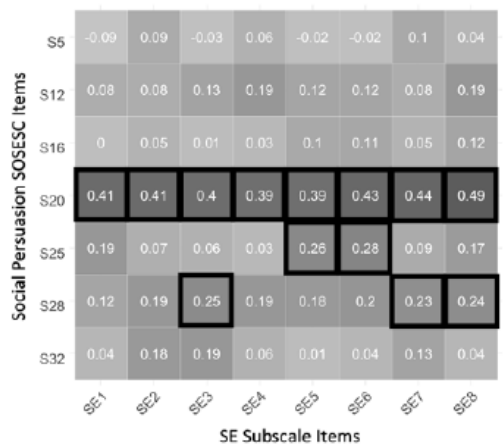

Supplementary Figure 1: Pearson's correlation matrix between eight items on the SE subscale (columns) and SOSESC subscale items (rows). The SOSESC item rows are labeled by subscale abbreviation and item number in the 33 -item metric. Shading represents the value of the correlation coefficient between 1.0 (black) and -1.0 (white). Pearson's correlation coefficient are within the boxes in white text; for $\boldsymbol{B}-\boldsymbol{E}$, significance at the $p<.05$ level is indicated by a black outline around the correlation coefficient. $A$. SE subscale items were all correlated with each other at the $p$ $<.0001$ level. B. The ten items of the Performance Accomplishment (PA) subscale had the highest number of correlations with the SE subscale; $80.0 \%$ of the pairwise comparisons correlated significantly with SE subscale items. $\boldsymbol{C}$. The nine Emotional Arousal (EA) items had $75.0 \%$ pairwise correlations with SE subscale items. $\boldsymbol{D}$. The seven items of the Vicarious Learning (VL) subscale correlated moderately with the SE subscale $51.8 \%$ of pairwise correlations). $\boldsymbol{E}$. The Social Persuasion (SP) subscale had the fewest significant correlations with the SE subscale $(23.2 \%)$. 


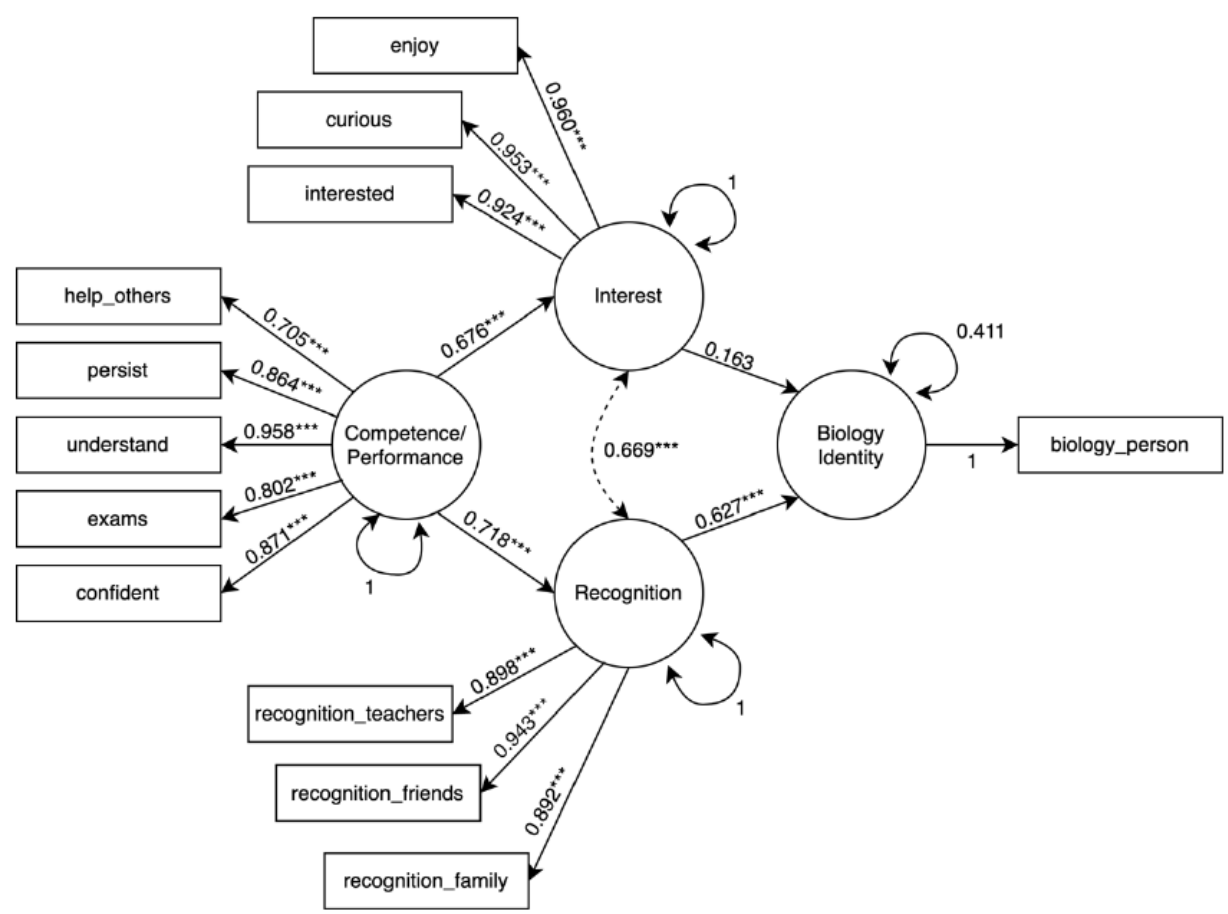

Supplementary Figure 2: Confirmatory Factor Analysis model for science identity, proposed by Cribbs et al. (2015). All paths in the model between latent variables in this model were significant except for the regression between Interest to Biology Identity.

Supplementary Table 1: Confirmatory Factor Analysis Factor Loadings for ID metric items

\begin{tabular}{|c|c|c|c|}
\hline Latent Variable & Label & Item & $\begin{array}{c}\text { Standardized } \\
\text { Factor } \\
\text { Loading } \\
\end{array}$ \\
\hline \multicolumn{4}{|l|}{ Biology Identity } \\
\hline & biology_person & I see myself as a biology person & 1.000 \\
\hline & recognition family & My family sees me as a biology person & 0.892 \\
\hline & recognition friends & My friends/classmates see me as a biology person & 0.943 \\
\hline & recognition_teachers & $\begin{array}{l}\text { My science instructors/teachers see me as a biology } \\
\text { person }\end{array}$ & 0.898 \\
\hline \multicolumn{4}{|c|}{ P } \\
\hline & understand & I am confident that I can understand biology & 0.871 \\
\hline & exams & I can do well on exams in biology & 0.802 \\
\hline & concepts & I understand concepts I have studied in biology & 0.958 \\
\hline & persist & I can overcome setbacks in biology & 0.864 \\
\hline & help_others & Others ask me for help in biology & 0.705 \\
\hline \multicolumn{4}{|l|}{ Interest } \\
\hline & interest & I am interested in learning more about biology & 0.924 \\
\hline & curiosity & Topics in biology excite my curiosity & 0.953 \\
\hline & enjoy & I enjoy learning about biology & 0.960 \\
\hline
\end{tabular}

Supplementary Table 2: Confirmatory Factor Analysis model fit indices for science identity. None of the fit indices fell within acceptable ranges (Hu \& Bentler, 1999).

\begin{tabular}{lcc}
\hline \multicolumn{1}{c}{ Fit Index } & Acceptable Value & Model Value \\
\hline Model & $p>.05$ & $=39.76, \mathrm{df}=51, p<.001$ \\
RMSEA & $<0.06$ & $0.145, \mathrm{CI} 0.118,0.172$ \\
SRMR & $<0.08$ & 0.085 \\
CFI & $>0.95$ & 0.923 \\
\hline
\end{tabular}

